\title{
Divergence and conservation of the partitioning and global regulation functions in the central control region of the IncP plasmids RK2 and R751
}

School of Biological Sciences, University of Birmingham, Edgbaston, Birmingham B15 2TT, UK

\author{
Donia P. Macartney, D. Ross Williams, Theresa Stafford \\ and Christopher M. Thomas
}

Author for correspondence: Christopher M. Thomas. Tel: +44 121414 5903. Fax: +44 1214145925. e-mail: c.m.thomas@bham.ac.uk

The central control region (CtI) of IncP plasmids is associated with two phenotypes: the coordinate expression of replication and transfer genes; and the ability to increase the segregational stability of a low-copy-number test plasmid. This region of the InCP $\beta$ plasmid R751 shows significant sequence divergence from the IncP $\alpha$ plasmid RK2 sequence, and two genes, korF and korG, present in the IncP $\alpha$ region are missing in the IncP $\beta$ CtI. In other respects the organization of the Ctl is basically the same. Although the two key global regulatory genes korA and korB are highly conserved, studies on their ability to repress transcription from a variety of IncP $\alpha$ and IncP $\beta$ plasmid promoters suggest differences in operator recognition by KorA and synergy with other repressors. The products of kfrA, upf54.8 and upf54.4 genes are conserved; KfrA shows least conservation and, while retaining the ability to act as a transcriptional repressor, appears to have completely different DNA-binding specificity. The genes required for the plasmid segregational stabilization (partitioning) phenotype - incC, korB and the KorB operator $\mathrm{O}_{\mathrm{B}} 3$ - are conserved and contribute to a more efficient plasmid stabilization than the IncP $\alpha$ equivalents. This may indicate that the CtI plays an especially important role in partitioning of IncP $\beta$ plasmids, since they lack the second stability region (par/mrs) found in IncP $\alpha$ plasmids.

Keywords: plasmid R751, IncP $\beta$ plasmids, plasmid partitioning, transcriptional repressor KorA, transcriptional repressor KorB

\section{INTRODUCTION}

IncP plasmids have been studied because of their ability to transfer between and stably maintain themselves in almost all Gram-negative bacterial species (Thomas \& Smith, 1987; Thomas \& Helinski, 1989; Guiney \& Lanka, 1989; Pansegrau et al., 1994). Their conjugation system, which is related to many other conjugation systems including the vir system of $\mathrm{Ti}$ plasmids which transfers T DNA from Agrobacterium species to plant cells (Lessl et al., 1992b; Pansegrau et al., 1993), can

\footnotetext{
Abbreviations: $\mathrm{Ctl}$, central control region.

Plasmid gene nomenclature: all genes are designated by the names of their homologues in RK2.

The GenBank accession number for the sequence reported in this paper is L13688.
}

promote transfer from Gram-negative bacteria to Grampositive bacteria and to yeast (Trieu-Cuot et al., 1987; Heinemann \& Sprague, 1989; Sikorski et al., 1990).

A unique feature of IncP plasmids is the coordinate regulation of their replication and transfer functions by three global regulators: KorA, KorB and TrbA (reviewed by Pansegrau et al., 1994; Zatyka et al., 1994). Kor $A$ and KorB are encoded within the central control operon (Bechhofer \& Figurski, 1983; Theophilus \& Thomas, 1987), while TrbA is encoded at the start of the trb operon (Jagura-Burdzy et al., 1992), which contains most of the genes required for mating-pair formation (Lessl et al., 1992a, 1993). The plasmid region encompassing the central control operon also shows a stability (Par) phenotype: when linked to an unstable low-copy-number plasmid it will decrease its rate of loss (Motallebi-Veshareh et al., 1990). This phenotype was 
deliberately studied after sequence alignments showed that IncC (the first gene in the central control operon) and KorB belonged to an ubiquitous family of proteins encoded by plasmids and chromosomes and associated with partitioning or cell division (Motallebi-Veshareh et al., 1990). The family of Par proteins has grown steadily since it was recognized 6 years ago and there is increasing interest in what these proteins do (Williams \& Thomas, 1992; Wake \& Errington, 1995; Lobocka \& Yarmolinsky, 1996). In IncP plasmids they, or at least KorB, have clearly been recruited to coordinate gene expression as well. Studying the evolution of these and associated genes within the IncP family will help to elucidate their structure and function.

Southern blot analysis of HaeII restriction fragments of IncP plasmids using the oriT region of $\mathrm{RK} 2$ as a probe first revealed subdivision of the plasmids into $\alpha$ and $\beta$ subgroups (Yakobson \& Guiney, 1983). Similar analyses using ori $\mathrm{V}$ and part of the trfA gene from RK2 (Chikami et al., 1985) and the pri region from RP4 (Lanka et al., $1985)$ confirmed this. Although the IncP $\beta$ plasmid R751 (Jobanputra \& Datta, 1974) and IncP $\alpha$ plasmid RK2 have very different restriction maps, the basic organization of their replication and transfer functions is the same (Villaroel et al., 1983; Pansegrau \& Lanka, 1987; Smith \& Thomas, 1987).

The conservation of the backbone functions of RK2 and R751 extends to a degree of functional cross-reactivity between the two plasmid groups: a combination of the Tra1/oriT region of $\mathrm{RK} 2$ and the Tra2 region of $\mathrm{R} 751$ produced a functional conjugal transfer system, as did the reverse combination (Meyer \& Shapiro, 1980); the IncP $\beta$ plasmids R751, R906 and R772 have been shown to suppress the host-lethal effects of the RK2 kilA and kilB loci (Figurski et al., 1982); RK2 korA and korB can suppress the R751 equivalent of the kilB locus; R751 $\operatorname{trf} A$ can allow replication to initiate at RK2 oriV; and the presence of RK2 trfA in trans allows replication initiation at R751 oriV (Smith \& Thomas, 1985).

In this paper we describe the organization and sequence of the R751 central control region (Ctl), the crossreactivity of control functions with those of RK2 and the conservation of the partitioning functions in R751. The studies reveal similarities and significant differences in both regulation and partitioning. These differences will help future studies unravel some of the mechanisms of action of these proteins.

\section{METHODS}

Bacterial strains, plasmids and growth conditions. Escherichia coli strains used were $\mathrm{K} 12$ strains $\mathrm{C} 600 \mathrm{~K}$ (thr-1 leu-6 thi-1 lacY1 supE44 ton-21 galK), MV10 (C600trpR $\Delta$ trpE5) and C strain C2110 (polA1 his rha) obtained from Professor D. R. Helinski, Department of Biology, UC San Diego, California, USA). The plasmids used or constructed during the study are shown in Table 1 . Bacteria were generally grown in L broth (Kahn et al., 1979) at $37^{\circ} \mathrm{C}$ or on L agar (L broth with $1.5 \%$, $\mathrm{w} / \mathrm{v}$, agar) supplemented with antibiotics as appropriate: benzylpenicillin, sodium salt $\left(100 \mathrm{mg} \mathrm{ml}^{-1}\right.$ in liquid media and
$300 \mathrm{mg} \mathrm{ml}^{-1}$ in agar plates) or ampicillin $\left(100 \mathrm{mg} \mathrm{ml}^{-1}\right)$ for penicillin resistance, kanamycin sulphate $\left(50 \mathrm{mg} \mathrm{m}^{-1}\right)$ for kanamycin resistance, tetracycline hydrochloride $\left(20 \mathrm{mg} \mathrm{ml}^{-1}\right)$ for tetracycline resistance and streptomycin sulphate $\left(50 \mathrm{mg} \mathrm{m}^{-1}\right)$ for streptomycin resistance.

Isolation, analysis and manipulation of plasmid DNA. Plasmid DNA was isolated by the alkaline SDS method of Birnboim \& Doly (1979) with slight modifications (Smith \& Thomas, 1983), and manipulated and analysed using standard techniques (Sambrook et al., 1989). Digestion of plasmid DNA with restriction enzymes was carried out under conditions recommended by the suppliers. Bacteria were made competent and transformed as described by Cohen et al. (1972). DNA sequencing was carried out by Alta Bioscience using the chaintermination method (Sanger et al., 1977) and an ABI 373 automated DNA sequencer. Sequences were aligned and analysed using programs of the Wisconsin package (Devereux et al., 1984).

Cloning using the polymerase chain reaction. Standard PCR reactions (Mullis et al., 1986) were performed as previously described by Jagura-Burdzy et al. (1992). Fragments were amplified on a pCT691 (hybrid of pRK229 and pACYC184, joined at the SalI sites: Thomas et al., 1988) template for RK2 and a pCT4712 template for R751. All PCR-derived clones were checked by DNA sequencing. The primers used were:

RK2 kfrAp, D4662DM 5'-CCCAAGCTTGGGGGAACGCGGCCTCGACTG-3'，D4663DM 5'-CGGAATTCCGGCCGCTGGCGTCGTTC-3';

RK2 korAp, D8139CT 5'-GGGAATTCTTGTTGGGCTGGCAGTGTCG-3', D8140CT 5'-GGGATCCTCCTGGAACTGGCTTTCGG-3';

R751 korAp, D8213DM 5'-GAGGATCCTGCAGTGTTCTACGACCAGGACG-3'，D8214DM 5'-CAGGATCCGAATTCAGCGAAGTGACAAACTCG-3';

R751 kfrAp, D7151DM 5'-CTGGCTCAACTACGAGGATG-3', D7151DM 5'-TCGCCTCGCTGATGGTGGTG-3';

R751 korAp-incC, D8213DM 5'-GAGGATCCTGCAGTGTTCTACGACCAGGACG-3', D8091CT 5'-GGGTCGACTCATTGCGCGATCTCCATCTTC-3'.

Construction of R751 incC and korB mutants. To construct inc $C$ and kor $B$ mutants, DNA of pCT4734 was digested with $B s m I$ or BspEI respectively. The BsmI-digested DNA was treated with T4 DNA polymerase and religated to produce a 2 bp deletion within inc C (pCT4734C). The BspEI-digested DNA was treated with DNA polymerase Klenow fragment in the presence of dNTPs and then religated in the presence of unphosphorylated PstI linkers (5'-GGCTGCAGCC- $\left.3^{\prime}\right)$ to give a 14 bp insertion in korB (pCT4734B). The HindIII fragments from $\mathrm{pCT} 4734 \mathrm{~B}$ and $\mathrm{pCT} 4734 \mathrm{C}$ were ligated to stability vector pOG04.

For regulation analyses a $\operatorname{kor} B$ mutation was created in the context of the complete $\mathrm{R} 751 \mathrm{Ctl}$. The korAp-incC region was amplified by PCR and the $1.3 \mathrm{~kb}$ product purified, digested with BamHI and Sall and introduced into pUC18 to give pDM2.16. EcoRI/BsmI digestion of pDM2.16 gave a fragment which was used to replace the equivalent EcoRI/BsmI fragment from pCT4734B, generating a complete R751 Ctl carrying the korB mutation (pCT4712B).

Construction of a modified $x y / E$ promoter-probe plasmid. Promoter-probe vector pPT01, a derivative of pGBT43 (Jagura-Burdzy et al., 1992) in which the EcoRI site is deleted, was digested with Bam HI, treated with DNA polymerase 
Table 1. Plasmids used in this study

\begin{tabular}{|c|c|c|c|c|c|}
\hline Plasmid & Size $(\mathbf{k b})$ & Replicons & $\begin{array}{l}\text { Selectable } \\
\text { marker* }\end{array}$ & Other properties & Reference/source $\dagger$ \\
\hline $\mathrm{R} 300 \mathrm{~B}$ & $8 \cdot 6$ & IncQ & $\mathrm{Sm}^{\mathrm{r}} \mathrm{Su}^{\mathrm{r}}$ & & Barth \& Grinter (1974) \\
\hline pALA1029 & $8 \cdot 5$ & pMB1, P7 & $A p^{r}$ & P7 par & Ludtke et al. (1989) \\
\hline pCT415 & $17 \cdot 0$ & IncQ & $\mathrm{Sm}^{\mathbf{r}}$ & $\mathrm{RK} 2 k l a C-k f r A$ & Thomas \& Hussain (1984) \\
\hline pCT470 & $15 \cdot 4$ & pMB1 & $A p^{r}$ & pBR322 plus R751 Sall fragment from kb 0 to 11 & Smith \& Thomas (1985) \\
\hline pCT654 & $5 \cdot 0$ & pMB1 & $A p^{r}$ & $\mathrm{RK} 2$ kor $A p$ & Theophilus et al. (1985) \\
\hline pCT691 & 28 & $\mathrm{p} 15 \mathrm{a}$ & $\mathrm{Tc}^{\mathrm{r}} \mathrm{Cm}^{\mathrm{r}}$ & pACYC184 and pRK229 (RK2 $\Delta)$ cointegrate & Thomas et al. (1988) \\
\hline pCT720 & $15 \cdot 5$ & IncQ & $S m^{r} T c^{r}$ & RK2 kleAp & Thomas et al. (1988) \\
\hline pGBT37 & $6 \cdot 8$ & $\mathrm{pMB} 1$ & $A p^{r}$ & $\operatorname{lacl}^{q}$ tacp-RK2 korA & Jagura-Burdzy et al. (1992) \\
\hline pGBT43 & $9 \cdot 7$ & pSC101 & $\mathrm{Km}^{\mathrm{r}}$ & $x y l E$ promoter probe & Jagura-Burdzy et al. (1992) \\
\hline pMMB25 & $14 \cdot 9$ & IncQ & $A p^{r} S m^{r}$ & lacl ${ }^{q}$ tacp $x y l E$ & Bagdasarian et al. (1984) \\
\hline pMMV811 & $7 \cdot 4$ & pMB1 & $A p^{r}$ & $\operatorname{lacI}^{q}$ tacp-RK2 korB & Williams et al. (1993) \\
\hline pOG4 & $12 \cdot 7$ & $\mathrm{pMB} 1, \mathrm{P7}$ & $A p^{r}$ & $\mathrm{RK} 2 \mathrm{CtI}$ & Williams et al. (1993) \\
\hline pWS131 & $6 \cdot 4$ & pMB1 & $A p^{r}$ & $\operatorname{lacI}^{q} \operatorname{tacp}-\mathrm{RK} 2 \mathrm{kfr} A$ & Thomas et al. (1990) \\
\hline pUC18 & $2 \cdot 7$ & pMB1 & $A p^{r}$ & lacZ cloning vector & $\begin{array}{l}\text { Yanisch-Perron et al. } \\
\text { (1985) }\end{array}$ \\
\hline pCT470R & $15 \cdot 4$ & $\mathrm{pMB} 1$ & $A p^{r}$ & $\begin{array}{l}\text { pCT } 470 \text { with inversion of R751-derived PstI } \\
\text { fragment }\end{array}$ & \\
\hline pCT4704 & $10 \cdot 0$ & pMB1 & $A p^{r}$ & $\mathrm{R} 751$ korC-upf54.8, pCT470R deletion derivative & \\
\hline pCT4712 & $8 \cdot 5$ & pMB1 & $\mathrm{Ap}^{\mathrm{r}}$ & R751 kleB'-upf54.8, pCT4704 deletion derivative & \\
\hline pCT4720 & $4 \cdot 5$ & pMB1 & $A p^{r}$ & R751 kfr $A^{\prime}-u p f 54.8$, pCT4704 deletion derivative & \\
\hline pCT4734 & $7 \cdot 2$ & pMB1 & $\mathrm{Ap}^{\mathrm{r}}$ & $\mathrm{R} 751$ kor $A^{\prime}-$ upf54.8, pCT4704 deletion derivative & \\
\hline pCT4754 & $6 \cdot 3$ & pMB1 & $\mathrm{Ap}^{\mathrm{r}}$ & R751 inc $C^{\prime}-u p f 54.8$, pCT4704 deletion derivative & \\
\hline pDM1.1 & $11 \cdot 6$ & IncQ & $\mathrm{Sm}^{\mathrm{r}}$ & pMMB25 minus $\mathrm{Ap}^{\mathrm{r}}$ and $x y l E$ cassettes & \\
\hline pDM1.2 & $14 \cdot 6$ & IncQ & $\mathrm{Sm}^{\mathrm{r}} \mathrm{Tc}^{\mathrm{r}}$ & pDM1.1 plus $\mathrm{Tc}^{\mathrm{r}}$ orginating from $\mathrm{pCT} 720$ & \\
\hline pDM1.21 & $16 \cdot 0$ & IncQ & $\mathrm{Tc}^{r}$ & lacl ${ }^{q}$ tacp-RK2 kor $B$, derivative of pDM1.2 & \\
\hline $\mathrm{pDM} 2.1 \mathrm{E}$ & $4 \cdot 1$ & pMB1 & $A p^{r}$ & pUC18 plus RK2 korB from pMMV811 & \\
\hline pDM2.15 & $3 \cdot 1$ & pMB1 & $\mathrm{Ap}^{\mathrm{r}}$ & pUC18 plus R751 $k f r A p$ & \\
\hline pDM2.15E & $3 \cdot 1$ & pMB1 & $\mathrm{Ap}^{\mathrm{r}}$ & As pDM2.15 with EcoRI linkers in HindIII site & \\
\hline pDM2.16 & $4 \cdot 0$ & $\mathrm{pMB} 1$ & $\mathrm{Ap}^{r}$ & pUC18 plus R751 korAp-incC & \\
\hline $\mathrm{pDM} 2.6 \mathrm{E}$ & $3 \cdot 2$ & pMB1 & $A p^{r}$ & $\begin{array}{l}\text { pUC18 plus RK2 kfrAp, EcoRI linkers in HindIII } \\
\text { site }\end{array}$ & \\
\hline pDM3 & $9 \cdot 7$ & pSC101 & $\mathrm{Km}^{\mathrm{r}}$ & $x y l E$ promoter probe, derivative of pPT01 & \\
\hline pDM3.1 & $10 \cdot 4$ & pSC101 & $\mathrm{Km}^{\mathrm{r}}$ & RK2 kor $A p-x y l E$ promoter probe & \\
\hline pDM3.5 & $10 \cdot 1$ & pSC101 & $\mathrm{Km}^{\mathrm{r}}$ & $\mathrm{R} 751$ korAp-xylE promoter probe & \\
\hline pDM3.6 & $10 \cdot 1$ & pSC101 & $\mathrm{Km}^{\mathrm{r}}$ & R751 kfrAp-xylE promoter probe & \\
\hline $\mathrm{pDM} 300$ & $10 \cdot 2$ & pSC101 & $\mathrm{Km}^{\mathrm{r}}$ & RK2 $k f r A p-x y l E$ promoter probe & \\
\hline pOG04 & $6 \cdot 0$ & pMB1, P7 & $A p^{r}$ & Stability vector, pALA1029 deletion derivative & \\
\hline pOG0412 & $11 \cdot 5$ & pMB1, P7 & $A p^{r}$ & $\mathrm{R} 751 \mathrm{Ctl}$ & \\
\hline pOG0434 & $10 \cdot 5$ & pMB1, P7 & $A p^{r}$ & $\mathrm{R} 751$ inc $\mathrm{C} 2-u p f 54.4$ & \\
\hline pOG0434B & $10 \cdot 5$ & pMB1, P7 & $\mathrm{Ap}^{\mathrm{r}}$ & korB mutant of pOG0434 & \\
\hline pOG0434C & $10 \cdot 5$ & pMB1, P7 & $A p^{r}$ & inc $\mathrm{C}$ mutant of pOG0434 & \\
\hline pPT01 & $9 \cdot 7$ & pSC101 & $\mathrm{Km}^{\mathrm{r}}$ & $x y l E$ promoter probe, derivative of pGBT43 & \\
\hline
\end{tabular}

*Antibiotic-resistance markers are denoted as Ap, ampicillin ; Km, kanamycin; Tc, tetracycline; Cm, chloramphenicol ; Sm, streptomycin; and $\mathrm{Su}$, sulphonamide.

† Where no reference is shown, plasmids were derived in this study.

Klenow fragment in the presence of dNTPs and religated in the presence of unphosphorylated EcoRI linkers (5'CCGAATTCGG-3'). This generated a unique EcoRI site upstream of the $x y l E$ cassette (pDM3).

Construction of an IncQ expression vector and RK2 korB expression plasmid. The $x y l E$ cassette was removed from pMMB25 by EcoRI digestion and religation. The Ap ${ }^{r}$ marker was subsequently removed from this deletion derivative by
Pst I digestion and religation to give pDM1.1. A PstI fragment carrying the RK2 $\mathrm{Tc}^{\mathrm{r}}$ determinant (originating from pCT720) was introduced into $\mathrm{pDM} 1.1$ to give IncQ expression vector pDM1.2. Plasmid pDM2.1E is a pUC18 derivative in which RK2 korB has been introduced as an EcoRI/HindIII fragment from pMMV811, and unphosphorylated EcoRI linkers (see above) subsequently introduced into the HindIII site. The pDM2.1E EcoRI fragment carrying korB was introduced into pDM1.2 to give expression plasmid pDM1.21. 
Construction of RK2 korA and $k$ frA promoter-probe plasmids. The pCT654 EcoRI fragment which carries RK2 korAp was cloned into pDM3 to give $\mathrm{pDM} 3.1$. The RK2 kfrAp region was amplified using primers D4662DM and D4663DM, and introduced as an EcoRI/HindIII fragment into pUC18, giving pDM2.6. Insertion of unphosphorylated EcoRI linkers (see above) into the HindIII site gave pDM2.6E. The pDM2.6E EcoRI fragment carrying $k f r A p$ was introduced into pDM3 to give $\mathrm{pDM} 300$.

Construction of R751 korA and kfrA promoter-probe plasmids. The PCR-amplified korAp (primers D8213DM and $\mathrm{D} 8214 \mathrm{DM}$ ) was digested with $\mathrm{Bam} \mathrm{HI}$ and introduced into the $x y l E$ promoter-probe vector $\mathrm{pDM} 3$ to give $\mathrm{pDM} 3.5$. The $k f r A p$ region was amplified using primers D7150DM and D7151DM and introduced into the pUC18 HincII site, giving pDM2.15. Insertion of unphosphorylated EcoRI linkers (see above) into the HindII site gave pDM2.15E. The pDM2.15E EcoRI fragment carrying the $k f r A p$ was introduced into $\mathrm{pDM} 3$ to give pDM3.6.

Determination of XylE activity. Catechol 2,3-dioxygenase (the product of $x y l E$ ) activity was assayed in exponentially growing cells $\left(\mathrm{OD}_{600}\right)$ as described by Zukowski et al. (1983). One unit of enzyme activity is defined as the amount required to convert $1 \mu \mathrm{mol}$ substrate to product in $1 \mathrm{~min}$ under standard conditions. Where appropriate tacp was induced by addition of $1 \mathrm{mM}$ IPTG to the exponential-phase culture. Protein concentration was assayed by the biuret method (Gornall et al., 1949). Plasmids in the assay strains were checked by isolation and gel electrophoresis after restriction.

Estimation of the ability of R751 segments to stabilize a lowcopy-number plasmid. A shuttle vector, pOG04, was derived by deletion of the P7 par system from pALA1029. The vector replicates at high copy number in a pol $A^{+}$host from pMB1 origin and at low copy number in a polA host from $\mathrm{P7}$ origin. In polA strain C2110, pOG04 is lost during exponential growth at the rate expected of a randomly segregating plasmid present at $4-6$ copies per cell at division. Derivatives bearing wild-type and mutant $\mathrm{Ctl}$ regions from $\mathrm{R} 751$ were constructed and selected in a high-copy-number strain and then transformed into $\mathrm{C} 2110$ to test their stability. The transformants were subcultured in selective medium to $\mathrm{OD}_{600} 0 \cdot 8-1 \cdot 2$, diluted $10^{-6}$ into nonselective medium $\left(t_{0}\right)$ and grown for about 25 generations $\left(t_{\text {end }}\right)$. Viable counts were calculated at both $t_{0}$ and $t_{\text {end }}$ and the fraction of ampicillin-resistant colonies at both time-points calculated by replica-plating on $\mathrm{L}$ agar containing $100 \mathrm{mg}$ ampicillin $\mathrm{ml}^{-1}$. The mean apparent percentage loss of plasmid $\left(L_{\mathrm{a}}\right)$ was calculated using the formulae $L_{\mathrm{a}}=$ $\left(1-R^{1 / g}\right) \times 100$, where $R=\left(\% \mathrm{Ap}^{\mathrm{r}}\right.$ at $\left.t_{\text {end }}\right) /\left(\% \mathrm{Ap}^{\mathrm{r}}\right.$ at $\left.t_{0}\right)$ and $g$ (generations) $=\log _{\mathrm{e}}\left[x_{\text {end }} / x_{0}\right] / 0 \cdot 693$, where $x_{0}=$ viable count at $t_{0}$ and $x_{\text {end }}=$ viable count at $t_{\text {end }}$.

Visualization of polypeptide products by in vitro transcription and translation of plasmid DNA. Plasmid-encoded polypeptides were labelled with $\left[{ }^{35} \mathrm{~S}\right]$ methionine (DuPont NEN) using in vitro transcription/translation (Promega kit for circular molecules) on CsCl-purified plasmid DNAs ( $2 \mathrm{mg}$ ). Polypeptides were separated by SDS-PAGE and detected by phosphorimaging.

Analysis of protein-DNA interactions by gel retardation. DNA fragments were amplified by PCR using primers described above and labelled with terminal transferase and $[\alpha-$ ${ }^{32} \mathrm{P}$ ]ddATP. Radioactive fragments were incubated with previously purified RK2 KorA and KorB under the conditions previously described by Jagura-Burdzy \& Thomas (1995) and Williams et al. (1993) respectively. Samples were analysed as described in Jagura-Burdzy \& Thomas (1995).

\section{RESULTS AND DISCUSSION}

\section{Creation of a deletion series through the R751 central control region}

Analysis of the region of R751 encoding the central control operon started with cloning, into pBR322, the SalI fragment that runs from $\mathrm{kb}$ coordinate 0 to 11 on the standard map of R751 (Fig. 1), giving pCT470 (Smith \& Thomas, 1985). In attempting to delete the central PstI fragment from the clone this fragment was inverted (generating $\mathrm{pCT} 470 \mathrm{R}$ ), thus placing the expression of korC under the control of the constitutive pBR322 tet promoter, which may be an advantage when this region is joined to a high-copy-number plasmid. Bal31 deletions were generated from the unique $S s t$ II site of pCT470R and a HindIII linker was inserted. One of these deletion derivatives had lost all the DNA to within approximately $100 \mathrm{bp}$ of the KorB operator in the $u p f 54.4 / u p f 54.8$ intergenic region. This derivative was designated pCT4704; it still has korC, kleABEF, korA, inc $C, k o r B, k f r A$ and $u p f 54.8$. To remove DNA from the korC end, pCT4704 was digested to completion with BamHI and then partially digested with Sau3AI before ligation. This generated a family of deletions starting at

(a)
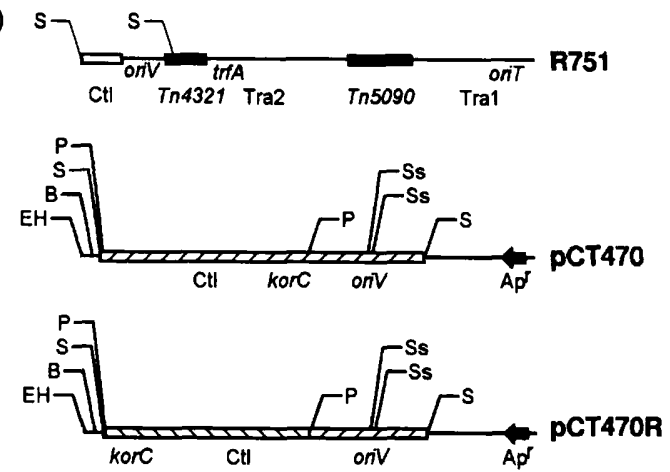

(b)

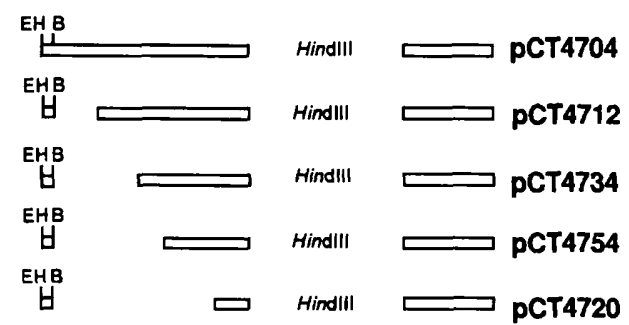

Fig. 1. Map of R751 and derived plasmids with the Ctl. (a) The genetic organization of R751 showing the location of the Ctl, the cis-acting and trans-acting factors required for vegetative replication (oriV and trfA respectively), the two regions carrying genes involved in conjugative transfer (Tra1 and Tra2) and including the cis-acting site required for transfer (orit), and the two transposable elements. The Sall (S) fragment introduced into PBR322 to produce PCT470 is indicated; other Sall sites are not shown. (b) The deletion series for the R751 CtI. pCT470R (identical to pCT470 except for an inverted Pstl fragment) was deleted to produce $\mathrm{pCT} 4704$, from which the $\mathrm{Ctl}$ deletions illustrated were generated. Restriction enzyme sites are indicated: B, BamHI; E, EcoRI; H, HindIII; P, Pstl; S, Sall; and Ss, Sstll. 

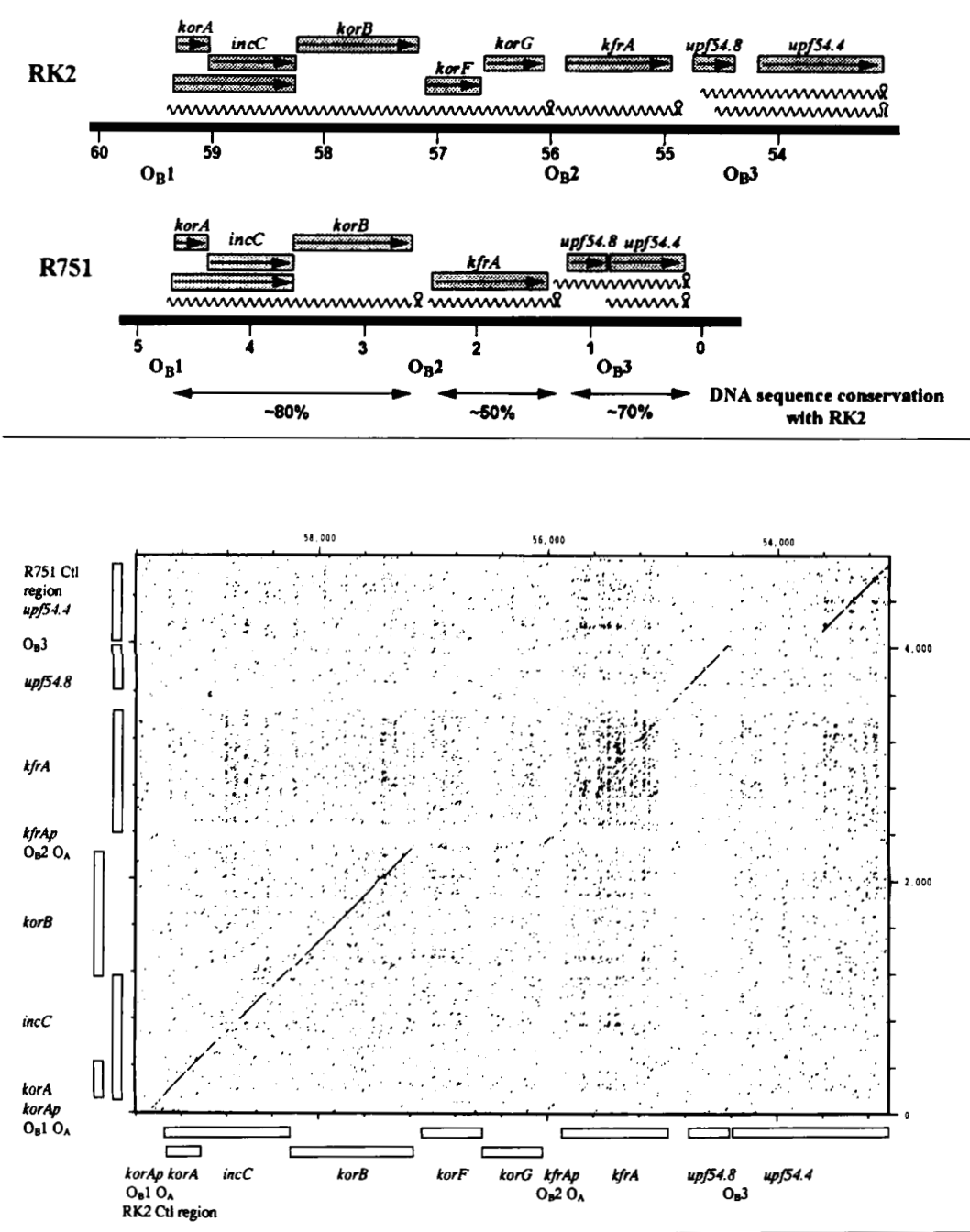

Fig. 2. Genetic organization of the RK2 and R751 Ctl. The DNA sequence conservation of R751 with RK2 is indicated. Numbers indicate plasmid $\mathrm{kb}$ coordinates and $\mathrm{O}_{\mathrm{B}}$ indicates the location of KorB operator sequences. DNA is illustrated as a solid black line, mRNA as $m$, putative rho-independent terminators as $\Omega$ and polypeptide ORFs as stippled boxes. the BamHI site and moving progressively into the R751 DNA. pCT4712, pCT4734, pCT4754 and pCT4720 had deletion end-points in the kleB, korA, inc $C$ and $k f r A$ genes respectively. Key plasmids in this series, illustrated in Fig. 1, were used to investigate the R751 functions in this region.

\section{Nucleotide sequence of the central control region of plasmid R751}

The nucleotide sequence of the region from $k o r A$ to upf54.4 was determined by a combination of shotgun cloning and sequencing of Sau3AI fragments from this region, sequencing of deletion derivatives, and sequencing with custom-designed oligonucleotides on a pCT470 template. The sequence is deposited in GenBank under accession number L13688. The main ORFs and other features of the sequence are presented in Fig. 2 and along the axes in Fig. 3. The G $+\mathrm{C}$ content of the R751 DNA is $66.5 \mathrm{~mol} \%$ on average, varying from $48 \mathrm{~mol} \%$ to $80 \mathrm{~mol} \%$ in a window of $100 \mathrm{bp}$. When the $\mathrm{G}+\mathrm{C}$ content was plotted it was very clear that there were local $A+T$-rich regions where promoters were located (data not shown).
Dot-matrix comparison showed blocks of conservation with IncP $\alpha$ sequences. However, there were a number of significant differences, particularly areas where sequences present in RK2 are absent from R751 (Fig. 3). The most obvious differences are the absence from R751 of korF, korG and the N-terminal region of upf54.4.

The overall percentage identity of the R751 genes with each equivalent $\mathrm{RK} 2$ gene is shown in Fig. 2. It varies from $79 \%$ for $k o r A$ to $54 \%$ for $k f r A$. The $k f r A$ gene stands out as peculiar in terms of high $\mathrm{G}+\mathrm{C}$ content (72 mol \%) and high divergence between RK2 and R751 genes. The dot-matrix comparison shows that there are many internally repeated sequences within the $k f r A$ gene (Fig. 3). These G + C-rich repeats could form the basis of illegitimate recombination to create deletions or duplications by unequal crossing over, or result in slipped mispairing to cause local expansion or contraction of the DNA.

The kor $A$ promoter region shows identical organization to that of RK2, with a KorB operator upstream of the -35 region and a Kor $A$ operator overlapping the -10 region. However, at the $k f r A$ promoter in $\mathrm{R} 751$ the KorB operator is directly adjacent to the KorA operator 
(a)
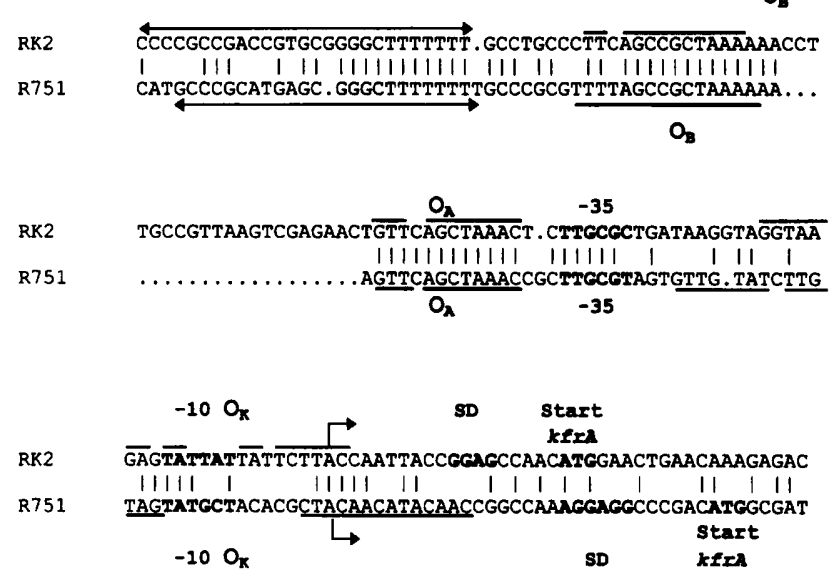

(b)

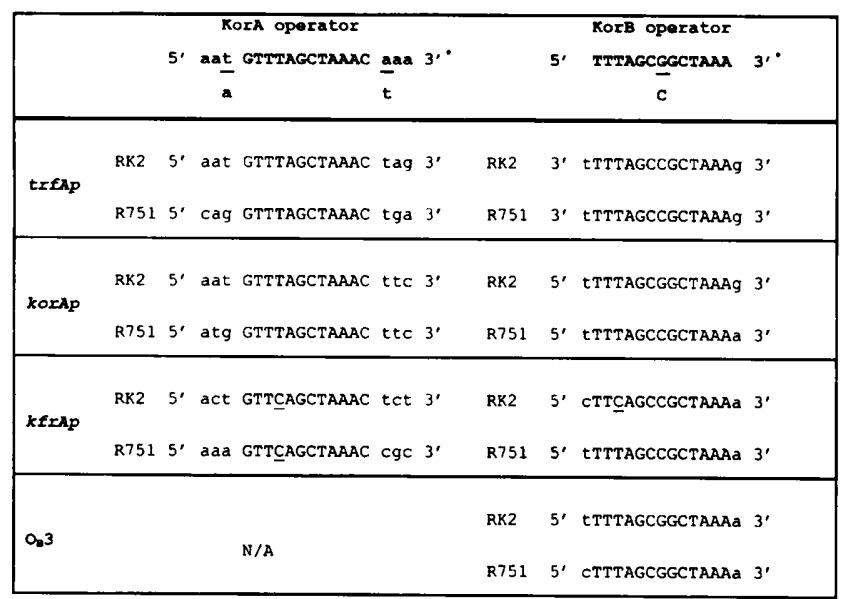

Fig. 4. (a) Alignment of the RK2 and R751 kfrAp regions. KorA $\left(O_{A}\right)$, KorB $\left(O_{B}\right)$, KfrA $\left(O_{K}\right)$ operators, promoter -10 and -35 sequences, transcriptional start points $(\rightarrow)$ based on primer extension mapping in RK2, putative rho-independent terminators $(\leftrightarrow)$, and translational signals, Shine-Dalgarno (SD) and start codons are shown. (b) Comparison of the $\mathrm{O}_{A}$ and $\mathrm{O}_{B}$ sequences in the RK2 and R751 korAp, kfrAp, trfAp and at $O_{B} 3$ in the intergenic region between upf54.8 and upf54.4. N/A indicates that a KorA operator is not present in this region.

(Fig. 4a), rather than separated from it by $24 \mathrm{bp}$. This organization is almost identical to that at the $k l c A$ promoter of R751 (Thomas et al., 1995). It may be that in $\mathrm{R} 751$ the KorA and KorB operators $\left(\mathrm{O}_{A}\right.$ and $\mathrm{O}_{B}$ respectively) are too close to allow both proteins to bind simultaneously. However, the centres of the operators are separated by $15 \mathrm{bp}$ ( 1.5 turns of the helix), which is consistent with the idea that KorA and KorB may bind to opposite faces of the DNA.

The core operators for KorA and $\operatorname{KorB}, \mathrm{O}_{\mathrm{A}}$ and $\mathrm{O}_{\mathrm{B}}$, are generally conserved between the two plasmids (Fig. $4 \mathrm{~b}$ ). However, there is considerable divergence in the flanking sequences of $\mathrm{O}_{\mathrm{A}}$. At $\mathrm{R} 751 \mathrm{kfrAp}$ the $\mathrm{O}_{\mathrm{B}}$ does not have the $\mathrm{T} \rightarrow \mathrm{C}$ transition which is present in RK2, and the palindrome extends for $15 \mathrm{bp}$ rather than $13 \mathrm{bp}$. A similar 15 bp palindrome is found at $\mathrm{RK} 2 \mathrm{O}_{\mathrm{B}} 3$ (Fig. 4 b).

\section{Conservation of the predicted polypeptides}

To check that the predicted polypeptides were produced, purified DNA of pCT4712 was used for in vitro transcription and translation analysis, which yielded products of the predicted sizes. The most highly conserved ORFs are korA (predicted polypeptides $88 \%$ identity) and kor $B$ (predicted polypeptides $84 \%$ identity). The C-terminal regions (amino acids $67-100$ ) of the RK2 and R751 KorA proteins are almost identical and are highly conserved with RK2 TrbA and KlcB (Thomas et al., 1995; Jagura-Burdzy \& Thomas, 1995). However, the putative $\alpha$-helix-turn- $\alpha$-helix motif (amino acids 38-57; Thomas \& Smith, 1986), thought to be responsible for operator recognition, shows four changes (E39T, V41A, K48R and S57H), which may be significant in light of the differences described below.

KorB is highly conserved despite two gaps in the alignment towards the $\mathrm{C}$ terminus. The $\alpha$-helix-turn $-\alpha$ helix motif (amino acids 164-182), which we proposed for the RK2 KorB (Theophilus \& Thomas, 1987) and which appears to be conserved in homologues of KorB (Lobocka \& Yarmolinsky, 1996), is highly conserved, while the $\mathrm{N}$ terminus (amino acids $1-49$ ) and the third quarter of the proteins (amino acids 190-285) are more divergent.

IncC shows $59.5 \%$ identity with RK2 IncC. The Nterminal 100 aa of IncC1 (the larger incC product arising from the first of two translational starting points in the inc C ORF), whose coding region overlaps that of korA, show $60 \%$ identity. Much higher conservation is seen for the ATP-binding motifs (amino acids 114-121, 132-142 and 219-228; Motallebi-Veshareh et al., 1990), while the rest shows a surprising amount of divergence, including a 70 aa stretch with very little conservation. This is not due to an error at the DNA sequence level. Codon preference analysis revealed no evidence for such errors. Since IncC and KorB function as a pair it will be interesting to determine whether the degree of divergence in IncC prevents cross-complementation of partitioning functions between RK2 and R751.

KfrA shows considerable divergence (only $47 \%$ identity). The $\mathrm{N}$-terminal region (amino acids $1-80$ ), previously proposed to encode a DNA-binding motif (Jagura-Burdzy \& Thomas, 1992), is not conserved and this fits with changed regulatory specificity (see below). A key feature noted for RK2 KfrA is its high $\alpha$-helical content (Jagura-Burdzy \& Thomas, 1992). Computer analysis predicts that the same is true for R751 KfrA.

Interestingly, $u p f 54.4$ and $u p f 54.8$, for which there are no identified functions, are more highly conserved than either inc C or $k f r A$. The conservation in $u p f 54.8$ varies from perfect alignment to gaps with no similarity, and the predicted product shows sequence similarity to TraA of the IncP $\alpha$ plasmids (Pansegrau et al., 1994), which is not present in the IncP $\beta$ genome (Thorsted et al., 1996). The upf54.4 ORF lacks the first 200 aa present 
Table 2. Regulation of korAp, KfrAp and trfAp by repressors of RK2 and R751

\begin{tabular}{|c|c|c|c|c|c|c|c|}
\hline \multirow{2}{*}{$\begin{array}{l}\text { pMB1 plasmid } \\
\text { in trans }\end{array}$} & \multirow{2}{*}{$\begin{array}{l}\text { Genetic loci, } \\
\text { pMB1 replicon }\end{array}$} & \multirow{2}{*}{$\begin{array}{l}\text { IncQ plasmid } \\
\text { in trans }\end{array}$} & \multicolumn{5}{|c|}{ Mean relative catechol 2,3-dioxygenase activity* } \\
\hline & & & $\begin{array}{l}\text { RK2 kor } A p \\
\text { pDM3.1 }\end{array}$ & $\begin{array}{l}\text { R751 kor } A p \\
\text { pDM3.5 }\end{array}$ & $\begin{array}{l}\text { RK2 kfr } A p \\
\text { pDM300 }\end{array}$ & $\begin{array}{c}\text { R751 kfr } A p \\
\text { pDM3.6 }\end{array}$ & $\begin{array}{c}\text { RK2 } \operatorname{trf} A p \\
\text { PGBT58 }\end{array}$ \\
\hline pGBT37† & RK2 korA & None & $0.003 \pm 0.001$ & $0 \cdot 12 \pm 0 \cdot 06$ & $0 \cdot 13 \pm 0 \cdot 01$ & $0.38 \pm 0.06$ & $0 \cdot 004 \pm 0 \cdot 001$ \\
\hline pMMV811 & RK2 kor $B$ & Non & $0 \cdot 24 \pm 0 \cdot 10$ & $0 \cdot 51 \pm 0 \cdot 10$ & $0 \cdot 12 \pm$ & $0 \cdot 17 \pm 0 \cdot 04$ & $0.09 \pm 0.02$ \\
\hline pWS131† & $\mathrm{RK} 2 k f r A$ & None & ND & $\mathrm{ND}$ & $<0.002$ & $1 \cdot 1 \pm 0 \cdot 35$ & $\mathrm{ND}$ \\
\hline pCT415 & $\begin{array}{l}\mathrm{RK} 2 \text { kor } A \text { inc } \mathrm{C} \text { kor } B \\
\text { korF kor } \mathrm{kfr} A\end{array}$ & None & $8 \pm 0.004$ & $<0.002$ & $0 \cdot 13 \pm 0 \cdot 03$ & $0 \cdot 86 \pm 0 \cdot 17$ & $0.012 \pm 0.004$ \\
\hline pCT4712\$ & $\mathrm{R} 751$ korA inc $\mathrm{C}$ kor $B$ kfrA & None & $0.006 \pm 0.002$ & $0.003 \pm 0.002$ & $0.36 \pm 0.04$ & $0.009 \pm 0.005$ & $0.007 \pm 0.004$ \\
\hline pCT4 & $\mathrm{R} 751$ korA & None & $0 \cdot 16 \pm$ & & $0.69 \pm 0.08$ & $0.012 \pm 0.001$ & \pm 0.02 \\
\hline pCT4712B $\|$ & $\mathrm{R} 751$ korA $i$ & pDM1.2 vector & ND & 0.04 & ND & ND & $0 \cdot 88 \pm 0 \cdot 24$ \\
\hline pCT4712B $\|$ & $\mathrm{R} 751$ korA inc C kfrA & $\begin{array}{c}\mathrm{pDM} 1.21 \mathrm{RK} 2 \\
\text { kor } B\end{array}$ & ND & $0.011 \pm 0.005$ & ND & ND & $1 \cdot 23 \pm 0 \cdot 25$ \\
\hline pCT4734\$ & $\mathrm{R} 751$ korB inc $\mathrm{C} 2$ kfr $A$ & None & $1 \cdot 23 \pm 0.22$ & $2 \cdot 07 \pm 0 \cdot 11$ & $0.97 \pm 0.16$ & $0.003 \pm 0.002$ & ND \\
\hline pCT4754\$ & $\mathrm{R} 751$ kor $B$ kfr $A$ & None & $1 \cdot 18 \pm 0 \cdot 30$ & $1 \cdot 31 \pm 0.08$ & $1 \cdot 09 \pm 0 \cdot 10$ & $0.009 \pm 0.006$ & ND \\
\hline
\end{tabular}

ND, Not done.

* Mean relative activities for at least four experimentally determined values $\pm 95 \%$ confidence limits.

† Catechol 2,3-dioxygenase activity of an induced culture relative to an induced control culture containing expression vector pGBT30 and the appropriate promoter-probe plasmid.

₹Catechol 2,3-dioxygenase activity of culture relative to a control culture containing R300B and the appropriate promoter-probe plasmid. $\$$ Catechol 2,3-dioxygenase activity of culture relative to a control culture containing pCT4720 and the appropriate promoter-probe plasmid.

\| Catechol 2,3-dioxygenase activity of culture relative to a control culture containing pCT4720, and the appropriate IncQ and promoterprobe plasmids.

in the RK2 equivalent but otherwise shows considerable identity. A particular feature of these proteins is the high glutamine content. Given the degree of divergence that has taken place in this region, the conservation of these ORFs between the two subfamilies argues for a significant role in plasmid survival.

\section{Functional conservation and divergence of the global regulatory genes korA and korB}

Both KorA and KorB are key regulators of the IncP plasmids and, as expected, the DNA sequence analysis shows that they are highly conserved. Nevertheless, there are enough sequence differences to make it possible that the specificity of binding to DNA may not be identical for the members of each pair. To assess the extent of functional (regulatory) conservation we studied the effect of the regulatory genes from RK2 and R751 on the RK2 trfAp, korAp and kfrAp and the R751 korAp and $k f r A p$. To make this possible, $x y l E$ promoter-probe plasmids were constructed using PCR to amplify and clone $k f r A p$ of RK2 and the R751 korAp and $k f r A p$. The RK2 korAp was obtained from plasmid pCT654. We used RK2 korA (pGBT37), korB (pMMV811) and the whole $\mathrm{Ctl}$ (pCT415) to demonstrate that repression was as expected for the RK2 promoters, and that the R751 promoters were sensitive to Kor $\mathrm{A}$ and $\operatorname{Kor} \mathrm{B}$ as predicted by the presence of $\mathrm{O}_{A}$ and $\mathrm{O}_{\mathrm{B}}$ sequences within the promoter regions. Table 2 shows that RK2 KorA and
KorB repressed R751 korAp (pDM3.5) and kfrAp (pDM3.6), but less strongly than the equivalent RK2 promoters. Flanking bases play an important role in operator specificity and binding strength for RK2 KorA (Jagura-Burdzy \& Thomas, 1995). Examination of the $\mathrm{O}_{\mathrm{A}}$ sequences revealed that the bases flanking the core of the operator in R751 differed from those found in RK2 (Fig. 4b). These differences may represent a significant divergence between the two plasmids.

RK2 KfrA had no effect on R751 kfrAp (see below). Nevertheless, weak repression was observed for the whole RK2 Ctl (pCT415) on R751 kfrAp (pDM3.6). This must have been due to KorA and/or KorB expressed from the autogenously regulated korAp, indicating the importance of $\mathrm{KfrA}$ repression at $k f r A p$ when $\operatorname{kor} A, \operatorname{kor} B$ and $k f r A$ are in the normal regulatory context.

When we studied the effect of the R751 regulatory genes it was clear that the complete $\mathrm{Ctl}$ present on pCT4712 caused severe repression of all promoters except RK2 $k f r A p$ (pDM300). This can be explained if R751 KfrA has little effect on RK2 kfrAp. Inactivation of korB (pCT4712B) gave a significant reduction in the observed repression. The level of repression of the RK2 korAp (pDM3.1) was clearly reduced more than that for R751 korAp (pDM3.5), which again suggested differences in specificity. Placing RK2 korB in trans to the R751 korB mutant (pCT4712B) resulted in increased repression, 
but not restoration of the level observed for the intact R751 operon. Assays with two deletion derivatives (pCT4734 and pCT4754) which had lost korAp and kor $A$ and placed kor $B$ transcription under the control of the pBR322 tet promoter showed that there was little residual repression that could be attributed to KorB.

The results show that while there is clearly crossreaction between the repressors of the two plasmids and their targets, there seem to be clear differences in the effect of the repressors on the heterologous promoter. This suggests that there has been divergence of the operator recognition between the two plasmids.

\section{Gel-retardation assays of RK2 KorA and KorB affinities on RK2 and R751 operators}

The transcriptional regulation studies described above suggested that RK2 KorA and KorB had a stronger effect on RK2 promoter/operators than on R751 promoter/ operators. To test whether this was due to different affinities of the proteins for the RK2 and R751 operators we labelled DNA fragments containing either korAp or $k f r A p$ and used gel-retardation analyses to study the binding of purified RK2 KorA and KorB to these fragments. The labelled $k f r A p$ fragments for both RK2 and R751 were digested with $\mathrm{MboII}$ and $\mathrm{N} c i$ I respectively to produce smaller DNA fragments for retardation.

Specific binding of RK2 KorA and KorB to the DNA containing their operators in the $k f r A p$ fragments is demonstrated in Fig. 5(a). No difference was observed for KorA at either $k f r A p$ operator. KorB may have a slightly higher affinity for its operator in R751 kfrAp. More significantly, KorB forms a second retarded complex with R751 kfrAp, but not with RK2 kfrAp. These differences may reflect either or both the facts that in $R 751$ the $\mathrm{O}_{\mathrm{B}}$ inverted repeat is $15 \mathrm{bp}$ compared with 13 bp in RK2, and that the R751 operator does not have the $\mathrm{T} \rightarrow \mathrm{C}$ transition present in RK2, which we think reduces affinity for KorB.

When the korAp fragments were studied, RK2 KorA was demonstrated to bind the RK2 korAp with high affinity and the R751 korAp with much lower affinity (Fig. 5b). RK2 KorB was shown to have high binding affinity for both the RK2 and R751 korAp regions and in both cases formed the more slowly migrating complexes observed for RK2 (Fig. 5b). Thus, there seem to be significant differences in KorA-DNA interactions which are due to differences in the target sites.

\section{The specificities of R751 and RK2 kfrA genes are completely different}

The $k f r A$ genes of R751 and RK2 show the greatest divergence of all the ORFs present in this region of both plasmids. In addition, the operator identified in RK2 as the binding site for KfrA (Jagura-Burdzy \& Thomas, 1992) is not conserved in R751 (Fig. 4a). To test the prediction that there is no cross-reactivity between $\mathrm{KfrA}$ (a)

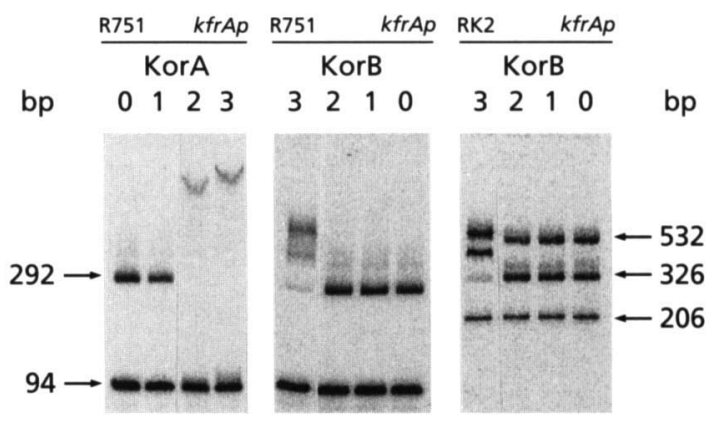

(b)

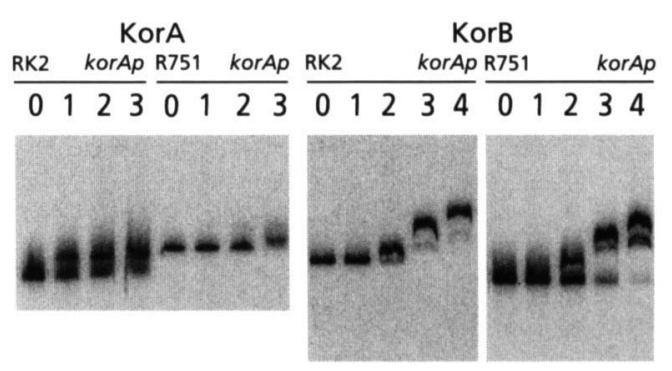

Fig. 5. Gel retardation using RK2 KorA and KorB proteins with fragments carrying the RK2 and R751 kfrAp and korAp regions. (a) Retardation of $k f r A p$ fragments. 0 indicates that neither KorA nor KorB is present. The values for KorA correspond to: 1 , $1 \mu \mathrm{g} ; 2,7 \mu \mathrm{g} ; 3,9 \mu \mathrm{g}$; and for KorB to: $1,18 \mathrm{ng} ; 2,54 \mathrm{ng} ; 3$, $540 \mathrm{ng}$. (b) Retardation of korAp fragments. 0 indicates that neither KorA nor KorB is present. The values for KorA correspond to: $1,1 \mu \mathrm{g} ; 2,3.3 \mu \mathrm{g} ; 3,10 \mu \mathrm{g}$; and for KorB to: 1 , $18 \mathrm{ng} ; 2,54 \mathrm{ng} ; 3,180 \mathrm{ng} ; 4,540 \mathrm{ng}$.

proteins and the heterologous $k f r A p s$, we determined the effects of plasmids carrying each gene against appropriate reporter plasmids (Table 2). The results showed that the tacp-kfrA $A_{\mathrm{RK} 2}$ plasmid pWS131 represses the $k f r A p_{\mathrm{RK} 2}-x y l E$ plasmid (pDM300) strongly but has no effect on the $k f r A p_{\mathrm{R} 751}-x y l E$ plasmid (pDM3.6). Conversely the $k f r A_{\mathrm{R} 751}$ plasmid pCT4754 represses pDM3.6 strongly but has no effect on pDM300.

We predict that the inverted repeat overlapping the $k f r A p$ of R751 is the operator for the KfrA of R751, since this is the location of the KfrA operator in RK2 kfrAp. This inverted repeat is very interesting because each half consists of direct repeats. Given the conservation of the other replication and regulation functions between RK2 and $\mathrm{R} 751$, the divergence of the $k f r A$ genes suggests that their function must be auxiliary, so that a mutation which inactivates $k f r A$ or its operator may not have a disastrous effect on plasmid survival.

\section{R751 exhibits a more efficient partitioning phenotype than IncP $\propto$ plasmids}

One of the key phenotypes of the $\mathrm{Ctl}$ in IncP $\alpha$ plasmids is the stability it confers on an unstable, low-copynumber heterologous replicon. To determine whether this phenotype is conserved in R751 we cloned the HindIII fragment containing this region from pCT4712 


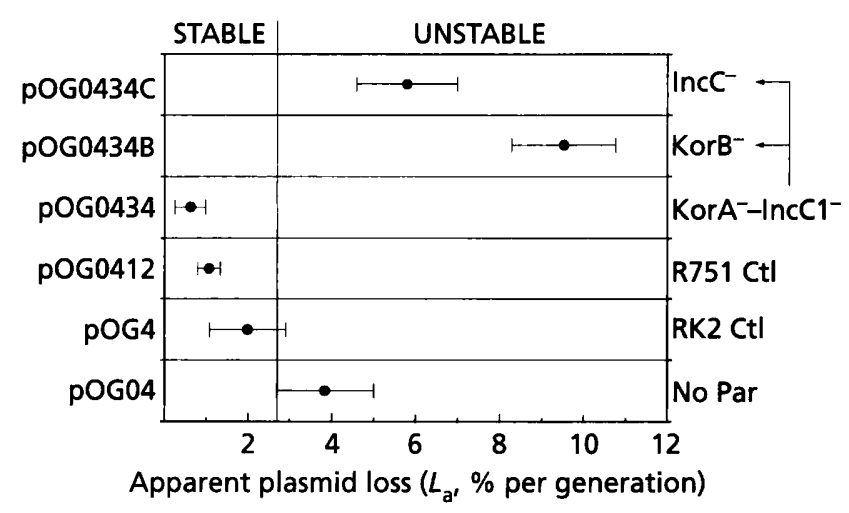

Fig. 6. Plasmid stability analysis. The mean apparent percentage loss $\left(L_{a}\right)$ for each plasmid is presented, including $95 \%$ confidence limits, as calculated from at least three independent experiments.

into stability test vector pOG04 to give pOG0412. Fig. 6 shows that the R751 Ctl (pOG0412) gave a stronger stabilization than the equivalent RK2 region (pOG4). Estimates of plasmid copy number by quantitative hybridization showed that the stabilization was not due to an increase in copy number (data not shown). This suggests that the R751 Ctl encodes a more efficient stability system than the RK2 Ctl. A deletion derivative (pCT4734) lacking the beginning of korA and incC1 was created in which the korA ORF was fused in phase with the tet ORF of $\mathrm{pBR} 322$. The remaining $\mathrm{R} 751 \mathrm{Ctl}$ was transferred to pOG04 as a HindIII fragment (pOG0434). Stability analysis revealed that this region was still able to stabilize pOG04 and suggested that $\mathrm{O}_{\mathrm{B}} 1$, korA and inc $\mathrm{C} 1$ are not needed for the stability system.

To check that the stabilization observed was similar to that found in the IncP $\alpha$ plasmid RK2, we inactivated incC (pOG0434C) and korB (pOG0434B) in the context of pCT4734 as described in Methods. Stability analyses (Fig. 6) confirmed that both incC2 and korB were needed for the stability phenotype.

\section{Conclusions}

The results confirm the previous observation that the basic organization of the $\operatorname{IncP} \alpha$ and $\operatorname{IncP} \beta$ plasmids is the same. They show that different regions have diverged to varying extents, which appears to reflect both functional constraints and inherent instability of particular gene sequences. The lack of korF/korG in R751 could be interpreted as loss of functions present in a common ancestor. However, since no known parAparB homologues of inc $C$ and $k o r B$ have been shown to be accompanied by $\operatorname{korF/korG~homologues~it~is~equally~}$ plausible that they were more recently acquired, perhaps in a similar way to that proposed as a possibility for the klaAtelAtelB genes in the RK2 kilA operon (Walter et al., 1991; Goncharoff et al., 1991; Thomas et al., 1995). Either way it shows that $k o r F$ and $k o r G$ are dispensable.

Although KorA and KorB and their operators are conserved, there appear to be significant differences in the specificity of repressor-operator interactions and possibly repressor-repressor synergy. Based on previous analysis of KorA-operator interaction (Jagura-Burdzy $\&$ Thomas, 1995) we proposed that this reflects changes in the sequences flanking the core operator. Such changes should be able to occur without disruption of essential interactions.

The R751 Ctl displays a stronger $\mathrm{Par}^{+}$phenotype than the equivalent RK2 region. This may correlate with the absence of a second partitioning function equivalent to the parABCDE region found in RK2.

The divergence between the plasmids may provide a natural means of exploring regions important for partitioning, particularly those which specify the interactions between subcomponents.

\section{ACKNOWLEDGEMENTS}

We thank Grazyna Jagura-Burdzy for helpful discussion. D.P.M. was supported by an MRC Studentship for training in research methods. D.R.W. was supported by MRC Project Grants G9231237CB and G8919550CB. Oligonuceotides were synthesized by Alta Bioscience. Automated DNA sequencing was performed by Alta Bioscience using an ABI373 machine purchased with a grant from The Wellcome Trust (038654/Z/93). The phosphorimager was purchased with grants from The Wellcome Trust $(037160 / \mathrm{Z} / 92)$ and the MRC (G9216078MB).

\section{REFERENCES}

Bagdasarian, M. M., Amann, E., Lurz, R., Rueckert, B. \& Bagdasarian, M. (1984). Activity of the hybrid trp-lac (tac) promoter of Escherichia coli in Pseudomonas putida: construction of broad-host-range, controlled expression vectors. Gene 26, 273-282.

Barth, P. T. \& Grinter, N. J. (1974). Comparison of the deoxyribonucleic acid molecular weights and homologies of plasmids conferring resistance to streptomycin and sulphonamide. $J$ Bacteriol 120, 618-630.

Bechhofer, D. H. \& Figurski, D. H. (1983). Map location and nucleotide sequence of korA, a key regulatory gene of promiscuous plasmid RK2. Nucleic Acids Res 11, 7453-7469.

Birnboim, H. C. \& Doly, J. (1979). A rapid alkaline extraction procedure for screening recombinant plasmid DNA. Nucleic Acids Res 7, 1513-1523.

Chikami, G. K., Guiney, D. G., Schmidhauser, T. J. \& Helinski, D. R. (1985). Comparison of ten IncP plasmids: homology in the regions involved in plasmid replication. J Bacteriol 162, 656-660.

Cohen, S. N., Chang, A. C. Y. \& Hsu, H. (1972). Non-chromosomal antibiotic resistance in bacteria: genetic transformation of Escherichia coli by R factor DNA. Proc Natl Acad Sci USA 69, 2110-2114.

Devereux, J., Haeberli, P. \& Smithies, O. (1984). A comprehensive set of sequence analysis programs for the VAX. Nucleic Acids Res 12, 387-395.

Figurski, D. H., Pohlman, R. F., Bechhofer, D. H., Prince, A. S. \& Kelton, C. A. (1982). Broad-host-range RK2 encodes multiple kil genes potentially lethal to Escherichia coli host cells. Proc Natl Acad Sci USA 79, 1935-1939.

Goncharoff, P., Saadi, S., Chang, C. H., Saltman, L. H. \& Figurski, 
D. H. (1991). Structural, molecular and genetic analysis of the kilA operon of broad-host-range plasmid RK2. J Bacteriol 173, 3463-3477.

Gornall, A. G., Bardawill, C. J. \& David, M. M. (1949). Determination of serum proteins by means of the biuret reaction. $J$ Biol Chem 177, 751-766.

Guiney, D. G. \& Lanka, E. (1989). Conjugative transfer in IncP plasmids. In Promiscuous Plasmids in Gram-negative Bacteria, pp. 27-54. Edited by C. M. Thomas. London: Academic Press.

Heinemann, J. A. \& Sprague, G. F. J. R. (1989). Bacterial conjugative plasmids mobilise DNA transfer between bacteria and yeast. Nature 340, 205-209.

Jagura-Burdzy, G. \& Thomas, C. M. (1992). $k f r A$ gene of broad host range plasmid RK2 encodes a novel DNA binding protein. $J$ Mol Biol 225, 651-660.

Jagura-Burdzy, G. \& Thomas, C. M. (1995). Purification of KorA protein from broad-host-range plasmid RK2: definition of a hierarchy of KorA operators. J Mol Biol 253, 39-50.

Jagura-Burdzy, G., Khanim, F., Smith, C. A. \& Thomas, C. M. (1992). Crosstalk between plasmid vegetative replication and conjugative transfer: regulation of the $\operatorname{tr} A$ operon by $\operatorname{trb} A$ of broad-host-range plasmid RK2. Nucleic Acids Res 20, 3939-3944.

Jobanputra, R. S. \& Datta, N. (1974). Trimethoprim R-factors in enterobacteria from clinical specimens. J Med Microbiol 7, 169-177.

Kahn, M., Kolter, R., Thomas, C. M., Figurski, D. H., Meyer, R., Remaut, E. \& Helinski, D. R. (1979). Plasmid cloning vehicles derived from plasmids ColE1, R6K and RK2. Methods Enzymol 68, 268-280.

Lanka, E., Fürste, J. P., Yakobson, E. \& Guiney, D. G. (1985). Conserved regions at the DNA primase locus of the IncP $\alpha$ and IncP $\beta$ plasmids. Plasmid 14, 217-223.

Lessl, M., Balzer, D., Lurz, R., Waters, V., Guiney, D. G. \& Lanka, E. (1992a). Dissection of IncP conjugative plasmid transfer definition of the transfer region Tra2 by mobilisation of the Tra1 region in trans. J Bacteriol 174, 2493-2500.

Lessl, M., Balzer, D., Pansegrau, W. \& Lanka, E. (1992b). Sequence similarity between the RP4 Tra2 and the Ti VirB regions strongly supports the conjugative model for T-DNA transfer. $J$ Biol Chem 267, 20471-20480.

Lessl, M., Balzer, D., Weyrauch, K. \& Lanka, E. (1993). The mating pair formation system of plasmid RP4 defined by RSF1010 mobilisation and donor-specific phage propagation. $J$ Bacteriol $175,6415-6425$.

Lobocka, M. \& Yarmolinsky, M. (1996). P1 plasmid partition - a mutational analysis of ParB. J Mol Biol 259, 366-382.

Ludtke, D. N., Eichorn, B. G. \& Austin, S. J. (1989). Plasmid partition functions of the P7 prophage. J Mol Biol 209, 393-406.

Meyer, R. J. \& Shapiro, J. A. (1980). Genetic organisation of the broad-host-range IncP-1 plasmid R751. J Bacteriol 143, 1362-1373.

Motallebi-Veshareh, M., Rouch, D. A. \& Thomas, C. M. (1990). A family of ATPases involved in active partitioning of diverse bacterial plasmids. Mol Microbiol 4, 1455-1463.

Mullis, K., Faloona, F., Scharf, S., Saiki, R., Horn, G. \& Erlich, H. (1986). Specific enzymatic amplification of DNA in vitro: the polymerase chain reaction. Cold Spring Harbor Symp Quant Biol 51, 263-273.

Pansegrau, W. \& Lanka, E. (1987). Conservation of a common backbone in the genetic organisation of the IncP plasmids RP4 and R751. Nucleic Acids Res 15, 2385.
Pansegrau, W., Schoumacher, F., Hohn, B. \& Lanka, E. (1993). Sitespecific cleavage and joining of single-stranded DNA by VirB2 protein of Agrobacterium tumefaciens Ti plasmids: analogy to bacterial conjugation. Proc Natl Acad Sci USA 91, 11538-11542.

Pansegrau, W., Lanka, E., Barth, P. T., Figurski, D. H., Guiney, D. G., Haas, D., Helinski, D. R., Schwab, H., Stanisich, V. A. \& Thomas, C. M. (1994). Complete nucleotide sequence of Birmingham IncP $\alpha$ plasmids: compilation and comparative analysis. J Mol Biol 239, 623-663.

Sambrook, J., Fritsch, E. F. \& Maniatis, T. (1989). Molecular Cloning: a Laboratory Manual, 2nd edn. Cold Spring Harbor, NY: Cold Spring Harbor Laboratory.

Sanger, F., Nicklen, S. \& Coulson, A. R. (1977). DNA-sequencing with chain-terminating inhibitors. Proc Natl Acad Sci USA 74, 5463-5467.

Sikorski, R. S., Michaub, W., Levin, H. L., Boeke, J. D. \& Hieter, P. (1990). Trans-kingdom promiscuity. Nature 345, 581-582.

Smith, C. A. \& Thomas, C. M. (1983). Deletion mapping of kil and kor functions in the $\operatorname{trf} A$ and $\operatorname{trbB}$ regions of broad host range plasmid RK2. Mol Gen Genet 190, 245-254.

Smith, C. A. \& Thomas, C. M. (1985). Comparison of the nucleotide sequences of the vegetative replication origins of broad-hostrange IncP plasmids R751 and RK2 reveals conserved features of probable functional importance. Nucleic Acids Res 13, 557-572.

Smith, C. A. \& Thomas, C. M. (1987). Comparison of the organisation of the genomes of phenotypically diverse plasmids of incompatibility group $\mathrm{P}$ : members of the $\operatorname{Inc} \beta \beta$ sub-group are closely related. Mol Gen Genet 206, 419-427.

Theophilus, B. D. M. \& Thomas, C. M. (1987). Nucleotide sequence of the transcriptional repressor gene $\operatorname{kor} B$ which plays a key role in regulation of the copy number of broad-host-range plasmid RK2. Nucleic Acids Res 15, 7443-7450.

Theophilus, B. D. M., Cross, M. A., Smith, C. A. \& Thomas, C. M. (1985). Regulation of the $\operatorname{trf} A$ and $\operatorname{trf} B$ promoters of broad-hostrange plasmid RK2. Identification of sequence essential for regulation by $\operatorname{trfB} /$ korA/korD. Nucleic Acids Res 13, 8129-8142.

Thomas, C. M. \& Helinski, D. R. (1989). Vegetative replication and stable maintenance of IncP plasmids. In Promiscuous Plasmids of Gram-negative Bacteria, pp. 1-25. Edited by C. M. Thomas. London: Academic Press.

Thomas, C. M. \& Hussain, A. A. K. (1984). The korB gene of broad-host-range plasmid RK2 is a major copy number control element which may act together with $\operatorname{trf} B$ by limiting $\operatorname{trf} A$ expression. EMBO J 3, 1513-1519.

Thomas, C. M. \& Smith, C. A. (1986). The $\operatorname{trf} B$ region of broad host range $\mathrm{RK} 2$ : the nucleotide sequence reveals inc $\mathrm{C}$ and key regulatory gene $\operatorname{trfB} /$ kor $A /$ korD as overlapping genes. Nucleic Acids Res 14, 4453-4467.

Thomas, C. M. \& Smith, C. A. (1987). Incompatibility group P plasmids: genetics, evolution and use in genetic manipulation. Annu Rev Microbiol 41, 77-101.

Thomas, C. M., Ibbotson, J. P., Wang, N., Smith, C. A., Tipping, R. \& Loader, N. M. (1988). Gene regulation of broad-host-range plasmid RK2: identification of three novel operons whose transcription is repressed by both KorA and KorC. Nucleic Acids Res 16, 5345-5359.

Thomas, C. M., Theophilus, B. D., Johnston, L. J., Jagura-Burdzy, G., Schilf, W., Lurz, R. \& Lanka, E. (1990). Identification of a 7 th operon on plasmid RK2 regulated by the korA gene product. Gene 89, 29-35.

Thomas, C. M., Smith, C. A., Ibbotson, J. P., Johnston, L. \& Wang, 
N. (1995). Evolution of the korA-oriV segment of promiscuous IncP plasmids. Microbiology 141, 1201-1210.

Thorsted, P. B., Shah, D. S., Macartney, D. P., Kostelidou, K. \& Thomas, C. M. (1996). Conservation of the genetic switch between replication and transfer genes of IncP plasmids but divergence of the replication functions which are major host-range determinants. Plasmid 36, 95-111.

Trieu-Cuot, P., Carlier, C., Martin, P. \& Courvalin, P. (1987). Plasmid transfer by conjugation from Escherichia coli to Grampositive bacteria. FEMS Microbiol Lett 48, 289-294.

Villaroel, R., Hedges, R. W., Maenhaut, R., Laemans, J., Engler, G., Van Montagu, M. M. \& Schell, J. (1983). Heteroduplex analysis of P-plasmid evolution: the role of insertion and deletion of transposable elements. Mol Gen Genet 189, 390-399.

Wake, R. G. \& Errington, J. (1995). Chromosome partitioning in bacteria. Annu Rev Genet 29, 41-67.

Walter, E. G., Thomas, C. M., Ibbotson, J. P. \& Taylor, D. E. (1991). Transcriptional analysis, translational analysis and sequence of the kilA-tellurite resistance region of plasmid RK2Ter. J Bacteriol 173, 1111-1119.

Williams, D. R. \& Thomas, C. M. (1992). Active partitioning of bacterial plasmids. J Gen Microbiol 138, 1-16.
Williams, D. R., Motallebi-Veshareh, M. \& Thomas, C. M. (1993). Multifunctional repressor KorB can block transcription by preventing isomerization of RNA polymerase-promoter complexes. Nucleic Acids Res 21, 1141-1148.

Yakobson, E. \& Guiney, D. G. (1983). Homology in the transfer origins of broad-host-range IncP plasmids: definition of two subgroups of P plasmids. Mol Gen Genet 192, 436-438.

Yanisch-Perron, C., Vieira, J. \& Messing, J. (1985). Improved M13 phage cloning vectors and host strains: nucleotide sequence of the M13mp18 and pUC19 vectors. Gene 33, 103-119.

Zatyka, M., Jagura-Burdzy, G. \& Thomas, C. M. (1994). Regulation of transfer genes of promiscuous IncP $\alpha$ plasmid $\mathrm{RK} 2$ : repression of Tra1 region transcription both by relaxosome proteins and by the Tra2 regulator TrbA. Microbiology 140, 2981-2990.

Zukowski, M. M., Gaffney, D. F., Speck, D., Kauffman, M., Findeli, A., Wisecup, A. \& Lecocq, J.-P. (1983). Chromogenic identification of genetic regulatory signals in Bacillus subtilis based on expression of a cloned pseudomonad gene. Proc Natl Acad Sci USA 80, 1101-1105.

Received 29 October 1996; revised 30 January 1997; accepted 14 March 1997. 